ENCYCLOPEDDIE Encyclopédie berbère

BERBERE

$34 \mid 2012$

34| Nemencha - Nybgenii

\title{
Numides / Numidae
}

Jehan Desanges

\section{OpenEdition}

Journals

Édition électronique

URL : https://journals.openedition.org/encyclopedieberbere/2770

DOI : 10.4000/encyclopedieberbere. 2770

ISSN : 2262-7197

\section{Éditeur}

Peeters Publishers

\section{Édition imprimée}

Date de publication : 5 octobre 2012

Pagination : 5668-5669

ISBN : 978-90-429-2718-6

ISSN : $1015-7344$

\section{Référence électronique}

Jehan Desanges, « Numides / Numidae », Encyclopédie berbère [En ligne], 34 | 2012, document N77, mis en ligne le 15 décembre 2020, consulté le 17 février 2022. URL : http://journals.openedition.org/ encyclopedieberbere/2770; DOI : https://doi.org/10.4000/encyclopedieberbere.2770

Ce document a été généré automatiquement le 17 février 2022.

(c) Tous droits réservés 


\title{
Numides / Numidae
}

\author{
Jehan Desanges
}

1 Des tribus restreintes de Numidae sont mentionnées çà et là, notamment par l'épigraphie, dans l'Afrique romaine, et même en dehors du cadre de la Numidie traditionnelle.

2 On pensera d'abord tout naturellement à Thubursicu, dit Numidarum (Khamissa, à $32 \mathrm{~km}$ au sud-ouest de Souk Ahras, AAA, f. 18, n 297, cf.

3 ILAlg I, 1268 : Nunidarum pour Numidarum !), où sont attestés deux personnages portant le titre de princeps gentis Numidarum (ILAlg, I, 1297 et 1341) ainsi que le culte d'un genius gentis Numidiae (ILAlg, I, 1226) par lequel la gens pourrait affirmer son éponymie par rapport à la région. La ville fut très probablement d'abord le lieu de rassemblement d'une tribu ou d'une confédération de tribus, comme il en fut sans doute de Capsa, Gightis ou Sufetula. Beaucoup plus à l'est, à Masculula ( $\mathrm{H}^{\mathrm{r}}$ Guergour, AATun., 1/50.000, $\mathrm{f}$. 40 [XXXVIII], $\mathrm{n}^{\circ} 1$ ), entre Le Kef et Chemtou, une inscription distingue les citoyens romains de résidents désignés comme «numides » (CIL VIII, 15.775). On connaît aussi des Numidae Chellenses à Hr Aïn Zouarine (AATun, 1/100 000, f. 29, entre les $n^{\text {os }} 79$ et 86), à $10 \mathrm{~km}$ à l'ouest sud-ouest d'Assuras (Zanfour). On notera que ces trois sites sont en Proconsulaire, en dehors de la province de Numidie créée sous Septime Sévère.

4 Beaucoup plus à l'ouest, la Table de Peutinger (segm. II, 5 - III, 1) porte au génitif, partitif semble-t-il, l'ethnonyme Numidarum à l'est de la voie Cuicul (Djemila)-Igilgili (Djidjelli) et plus près de ce port maurétanien que de Cuicul. L'implantation de Numides en Sitifienne est confirmée par deux bornes trouvées près d'El Guerria, à $3 \mathrm{~km}$ au sudouest de Bordj Medjana, à l'ouest de Bordj Bou Arreridj : un procurateur de Maurétanie Césarienne cantonne, sous Hadrien, une gens Numidarum (CIL, 8813 et 8814 ; AAA, f. 15, $\mathrm{n}^{\circ} 78$ ). Encore sensiblement plus à l'ouest, dans la région de Sufasar (probablement à Amoura, Oued Chorfa, ex-Dollfusville, AAA, f. 13, $\left.n^{\circ} 75\right)$, a existé un évêché Numid(i)ensis, attesté en 411 et 484 (Lancel, p. 1439). La présence de Numides en Maurétanie peut s'expliquer de deux façons très différentes : elle peut rappeler qu'à l'origine, les Maures ont pu être considérés comme une catégorie de Numides (Polybe, III, 33, 15 ; Tite-Live, XXIV $, 49,5$ ) et qu'en tout état de cause, les Masaesyles de l'Oranais étaient tenus pour des Numides et non pour des Maures (cf. N76. « Numidie préromaine »); mais il peut 
s'agir aussi d'éléments tribaux venus de la Numidie traditionnelle, soit par nomadisme, soit en raison d'un refoulement vers l'ouest et le sud-ouest pratiqué par l'autorité romaine. Reste à expliquer pourquoi le terme très général de « Numides » a été préféré au nom spécifique de la tribu. On observe un phénomène peut-être comparable pour les Afri* et pour les Mazices*.

\section{BIBLIOGRAPHIE}

DESANGES J., 1980 - « Permanence d'une structure indigène en marge de l'administration romaine : la Numidie traditionnelle », Ant. Afr. 15, (= Hommages à J. Lassus, II), p. 77-89.

LANCEL S., 1991 - Actes de la Conférence de Carthage en 411, IV (= Sources chrétiennes, n³73), Paris.

INDEX

Mots-clés : Antiquité, Onomastique, Tribu 